\title{
EXPANSÃO DA PRIVATIZAÇÃO/MERCANTILIZAÇÃO DO ENSINO SUPERIOR BRASILEIRO: A FORMAÇÃO DOS OLIGOPÓLIOS*
}

\author{
Vera LúCia Jacob Chaves*
}

\begin{abstract}
RESUMO: O objetivo principal deste artigo é apresentar uma análise crítica das políticas de expansão da educação superior, no Brasil, instituídas pós-LDB/1996, com a finalidade de identificar e discutir as novas configuraçooes dessa expansão, em especial a que vem sendo efetivada, a partir de 2007, com a criação de redes de empresas por meio da compra e (ou) fusão de instituições de ensino superior privadas do país, por empresas nacionais e internacionais de ensino superior e pela abertura de capitais destas nas bolsas de valores, configurando a formação de oligopólios. Para tanto, utilizamos como recurso metodológico a pesquisa bibliográfica, especificamente a consulta em fontes documentais diversas, em especial, web sites de empresas educacionais, bem como de órgãos da imprensa tradicional e da mídia eletrônica nacionais. Nas considerações finais, apontamos algumas tendências da mercantilização do ensino superior, no Brasil.
\end{abstract}

Palavras-chave: Expansão do ensino superior. Mercantilização. Privatização. Oligopólios.

\section{THE EXPANSION OF PRIVATIZATION AND MERCANTILIZATION OF BRAZILIAN HIGHER EDUCATION: THE FORMATION OF OLIGOPOLIES}

ABSTRACT: The main objective of this article is to present a critical analysis of the post-1996 LDB (Law of Basic Tenets and Guidelines of Brazilian Education) educational policies regarding the expansion

\footnotetext{
* Artigo revisado e atualizado da comunicação apresentada no xxix Simpósio Brasileiro e III Congresso Interamericano de Política e Administração da Educação, no dia 12 de agosto de 2009, na Universidade Federal do Espírito Santo (UFES), em Vitória.

** Doutora em Educação e professora do Programa de Pós-Graduação em Educação, Instituto de Ciências da Educação da Universidade Federal do Pará (UFPA).E-mail: vjacob@uol.com.br
} 
of higher education in Brazil. It seeks to identify and discuss the new configurations of that expansion. It focuses more particularly on the creation of nets of educational firms from 2007 on, showing that the acquisition or merging of Brazilian higher education private institutions by national and international educational firms that went public has yielded oligopolies. Its methodological resources come from a variety of documental sources, in particular websites of educational firms and the Brazilian traditional and electronic news agencies. Its final considerations point out some tendencies towards the mercantilization of higher education in Brazil.

Key words: Higher education expansion . Mercantilization. Privatization.

Oligopolies.

\section{Introdução}

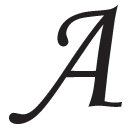

política de expansão do ensino superior brasileiro é parte da reforma do Estado implementada no país, a partir da década de 1990, chegando aos dias atuais. A centralidade dessa reforma consiste na redefinição do papel do Estado que reafirma, por um lado, o valor do Estado democrático e republicano como o âmbito natural da justiça e como instância estratégica de redistribuição de recursos, ao mesmo tempo em que ele é desmantelado, em função do reforço darwiniano do mercado, procurando, a qualquer custo, a manutenção dos lucros. Dessa forma, as bases da reforma do Estado brasileiro foram estabelecidas, em 1995 (governo Fernando Henrique Cardoso), por meio do Plano Diretor da Reforma do Estado (PDRE), ${ }^{1}$ que tem como principais diretrizes a privatização, a terceirização e a publicização.

A privatização vem sendo utilizada com a finalidade de reduzir a presença do Estado tanto na área produtiva, quanto na área social. Como consequência, as políticas sociais têm sido direcionadas à população de baixa renda, aliviando a miséria dos excluídos, mantendo, entretanto, a desigualdade social e a pobreza. $\mathrm{Na}$ área educacional, a política de focalização se manifesta por meio da priorização dos recursos da União para o atendimento ao ensino fundamental; pela criação de bolsas para os estudantes do ensino superior privado, a exemplo do Programa Universidade para Todos (PROUNI); ${ }^{2}$ e pela redução dos investimentos públicos nas instituiçôes de ensino superior (IES) públicas, 
induzindo-as à captação de recursos no mercado capitalista (Chaves, 2006). Assim, a educação superior deixa de ser direito social, transformando-se em mercadoria. A tese é de que o sistema de ensino superior deve se tornar mais diversificado e flexível, objetivando uma expansão com contenção nos gastos públicos. ${ }^{3}$

Dando curso a essa política, as instituições privadas de ensino superior foram estimuladas, pelos governos, a se expandir, por meio da liberalização dos serviços educacionais e da isenção fiscal, em especial, da oferta de cursos aligeirados, voltados apenas para o ensino desvinculado da pesquisa.

Neste estudo, interessa-nos investigar como ocorreu essa expansão, quais as configurações que o setor privado de ensino superior passou a ter, no período pós-LDB/1996, e, em particular, identificar as alterações ocorridas no processo de privatização/mercantilização da educação superior brasileira, a partir de 2007, com a inserção das IES privadas no mercado de ações do capital.

Dentre as diversas alterações adotadas no ensino superior brasileiro, desde então, e que acentuaram a privatização/mercantilização desse nível de ensino, destacaremos, neste texto, dois movimentos: 1) a fragmentação, por meio da diversificação institucional, e a expansão, pela via do setor privado; 2) a formação de oligopólios, no ensino superior privado, com a criação de redes de empresas por meio da compra e (ou) fusão de IES privadas do país, por empresas nacionais e internacionais de ensino superior e pela abertura de capitais destas nas bolsas de valores.

Para melhor compreensão do tema, iniciaremos com uma breve exposição, focalizando a reforma da educação superior, a partir da Lei de Diretrizes e Bases da Educação Nacional (LDB - Lei n. 9.394/1996), e sua relação com a crise do capitalismo e a reforma do Estado. Em segui$\mathrm{da}$, analisaremos a política de expansão do ensino superior privado, com ênfase no processo de diversificação das instituições e, posteriormente, deter-nos-emos na análise da nova configuração dessa expansão, com a criação dos oligopólios por meio de fusões das IES.

\section{A reforma da educação superior a partir da LDB n. 9.394/1996}

O debate sobre o ensino superior, no Brasil, tem sido marcado por conflitos ideológicos. Contudo, tanto por parte dos intelectuais do 
Expansão da privatização/mercantilização do ensino superior brasileiro...

governo como pelos seus críticos, existe consenso em apontar que, desde o final dos anos de 1970, com a crise do sistema capitalista iniciada nos países centrais e estendida a toda periferia do sistema, nas décadas de 1980 e 1990, houve necessidade da adoção de uma série de reformas estruturais, cuja centralidade residiu na desregulamentação dos mercados, na abertura comercial e financeira, na privatização do setor público e na redução do Estado.

Não é nossa intenção, neste estudo, fazer uma análise detalhada das causas dessa crise, mas, a partir das reflexões de alguns teóricos, identificar suas possíveis relações com a crise da universidade.

O modelo de acumulação fordista e o Estado de bem-estar social entraram em crise com a transnacionalização da economia; o avanço tecnológico e a substituição de uma tecnologia rígida por uma mais flexível e informatizada; as mudanças na organização do trabalho; a crise fiscal e a incapacidade do fundo público de continuar financiando a acumulação do capital e a reprodução da força de trabalho. A saída, apontada pelos neoconservadores, foi a defesa da volta às leis do mercado, sem restriçóes, e a retirada do Estado da economia, com a diminuição dos gastos públicos e dos investimentos em políticas sociais.

Como consequência, as reformas impostas pelo ajuste global do capitalismo visaram à abertura irrestrita ao mercado e à reorganização do espaço social, segundo sua própria racionalidade. Com isso, observou-se um movimento de reconfiguração das esferas pública e privada, afetando diretamente a educação, em geral, e a educação superior, em particular. Esse conjunto de fatos impõe uma ressignificação ao processo educativo, no campo das concepções e das políticas, cuja expressão maior, na América Latina, se concretizou nos anos de 1990, a partir de um movimento reformista, orientado pelos organismos internacionais, como o Fundo Monetário Internacional e o Banco Mundial.

As reformas educacionais exigidas desses países - em face de seus endividamentos externos - são orientadas em razão de financiamento. Como fontes de receita para superar o déficit público e estabilizar as convulsionadas economias da região, defendem a redução dos custos, o aumento da competitividade e a formação de recursos humanos mais produtivos.

Esse movimento de reforma do Estado capitalista, para adequarse ao novo modelo de acumulação flexível, se manifesta, no Brasil, de 
forma acentuada, por meio da mercantilização da educação, em especial do seu nível superior. Esse processo de mercantilização provoca mudanças substanciais na organização e no funcionamento do sistema nacional de ensino superior do país.

A ideia básica presente nas reformas educativas, iniciadas na década de 1990, é que os sistemas de ensino devem se tornar mais diversificados e flexíveis, objetivando maior competitividade com contenção de gastos. Seguindo essa diretriz, o governo brasileiro vem reformando a educação superior, por meio de uma diversidade de instrumentos normativos, como leis ordinárias, decretos, portarias, medidas provisórias etc., cuja centralidade reside na restrição de gastos. Essa reforma, em acordo com as recomendaçóes do Banco Mundial para os países da América Latina, fundamenta-se na lógica do mercado, na qualidade e na eficiência do sistema (produtividade e qualidade total), na avaliação quantitativa para concessão de recursos orçamentários, com controle finalístico, no empresariamento do ensino superior público, por meio da captaçáo de recursos no setor privado. Ou seja, o mercado passa a assumir a centralidade, na reforma republicana neoliberal, como ressalta Chauí (1999, p. 3):

A reforma do Estado tem um pressuposto ideológico básico: o mercado é, portanto, de racionalidade sócio-política e agente principal do bem estar da república. Esse pressuposto leva a colocar direitos sociais (como a saúde, a educação e a cultura) no setor de serviços definidos pelo mercado. Dessa maneira, a reforma encolhe o espaço público democrático de direitos e amplia o espaço privado não só ali onde seria previsível - nas atividades ligadas à produção econômica-, mas também onde não é admissível - no campo dos direitos sociais conquistados.

Como resultado dessa política, o ensino superior privado teve facilitado o seu crescimento, a um ritmo acelerado, ao mesmo tempo em que se reduziram drasticamente os recursos para a expansão e a manutenção das instituições públicas de ensino superior (Amaral, 2003). A Lei de Diretrizes e Bases da Educação Nacional (LDB), aprovada em 20 de dezembro de 1996, é considerada o marco legal da reforma implantada no país, na qual o Estado assumiu papel destacado no controle e na gestão das políticas educacionais, ao mesmo tempo em que liberalizou a oferta da educação superior pela iniciativa privada, como pode ser evidenciado no dispositivo legal a seguir: 
Expansão da privatização/mercantilização do ensino superior brasileiro...

Art. $7^{\circ}$ : $\mathrm{O}$ ensino é livre à iniciativa privada, atendidas as seguintes condições: I - cumprimento das normas gerais da educação nacional e do respectivo sistema de ensino; II - autorização de funcionamento e avaliação de qualidade pelo Poder Público; III - capacidade de autofinanciamento, ressalvado o previsto no art. 213 da Constituição Federal. (Brasil, 1996; grifos nossos)

Com esse artigo da LDB, fica clara a política a ser adotada, no país, em relação à educação, significando que a educação privada deve ser autofinanciada, cabendo à família arcar com seus custos, e o papel do Estado será apenas de regulador e controlador desse serviço, por meio da criação de mecanismos de credenciamento e avaliação.

No caso da educação superior, a LDB contribuiu para a intensificação da expansão do setor privado, ao admitir a existência e o funcionamento de instituições com fins lucrativos. Corroborando essa análise sobre a LDB, Catani e Oliveira (2007, p. 83) afirmam que ela

(...) promoveu a completa reestruturação da educação superior no país, em um processo que restringiu (e metamorfoseou) a atuação da esfera pública e ampliou a ação do setor privado, alterando de maneira significativa a identidade das IES, procurando tornar a educação um bem ou "produto", que os "clientes" adquirem no mercado universitário.

Assim, a LDB serviu como base para o processo de reforma da educação superior, em atendimento às orientaçôes dos organismos multilaterais internacionais para a implantação do modelo de Estado neoliberal, em que a lógica mercantilista assume a centralidade, como será evidenciado a seguir.

Expansão do setor privado: fragmentação e diversificação institucional

O primeiro movimento no sentido de implementar a fragmentação do ensino superior brasileiro foi estabelecido, legalmente, na LDB/ 1996, que define, no artigo 20, três tipos de instituições educacionais privadas: as particulares, em sentido estrito (empresariais); as comunitárias; as confessionais e filantrópicas.

A subdivisão do setor privado se apresenta, pois, em duas vertentes diferenciadas - de um lado, os estabelecimentos tidos como não lucrativos e, de outro, os que se apresentam como empresas destinadas 
a auferir lucro -, oferecendo nova configuração à disputa clássica entre os defensores da escola pública e os defensores da escola privada. Ao distinguirem-se das instituições lucrativas, as confessionais ou filantrópicas visam aproximar-se do setor público, reivindicando o acesso a verbas públicas. Utilizando a justificativa do seu caráter não lucrativo, estas instituições se autodenominam públicas não estatais. A aprovação da LDB, no entanto, favoreceu não apenas as instituiçôes ditas não lucrativas, mas também o setor empresarial, que almeja somente o lucro com as atividades educativas, quando possibilitou a institucionalização de outras modalidades de IES que não precisam, necessariamente, atuar com a premissa constitucional da indissociabilidade entre ensino, pesquisa e extensão, conferida às universidades por meio do artigo 207, da Constituição Federal de 1988.

Nesses mais de doze anos de vigência da LDB, os sucessivos governos neoliberais têm editado uma série de decretos, leis, portarias e outros instrumentos normativos com a finalidade de operacionalizá-la. No que se refere à diversificação institucional, destacam-se o Decreto n. 2.306, de 19 de agosto de 1997, instituído no governo de Fernando Henrique Cardoso, que regulamentou o Sistema Federal de Educação normatizando a tipologia e as atribuições das instituições de ensino superior, admitindo, de forma definitiva, as IES com fins lucrativos e estabelecendo, na referida tipologia, a diversificação daquelas instituições. As regras de organização do ensino superior e de avaliação de cursos foram alteradas, em 2001, pelas disposições do Decreto n. 3.860/2001, que consolidou a expansão do empresariamento do ensino superior, no Brasil.

O governo de Luís Inácio Lula da Silva dá continuidade a essa política privatista, por meio de novos instrumentos legais que favoreceram a expansão do setor educacional privado, como o Decreto n. 4.914, de $11 / 12 / 2003$, que concedeu autonomia aos centros universitários, e o Decreto n. 5.622, de 19/12/2005, que regulamenta a educação a distância (EaD) no Brasil, entre outros.

Esse conjunto de medidas legais fortalece e aprofunda a política de diversificação institucional e liberalização para a criação de instituições isoladas voltadas para o mercado, sendo decisivo para o crescimento explosivo do setor privado do ensino superior, no período pós-LDB.

Os dados do Instituto Nacional de Estudos e Pesquisas Anísio Teixeira (INEP) são reveladores da política privatista adotada no Brasil. 
Expansão da privatização/mercantilização do ensino superior brasileiro...

De acordo com o Censo do Ensino Superior (MEC/INep), no ano de 2007, foram registradas 4.880 .381 matrículas em cursos de graduação presenciais, sendo 1.240.968 destas em IES públicas e 3.639.413, em IES privadas, o que corresponde, respectivamente, a $25,4 \%$ e $74,6 \%$ do total de matrículas. Analisando-se o período de 1996 a 2007, verifica-se um crescimento de $161,2 \%$ no conjunto de alunos matriculados no ensino superior brasileiro; observa-se, no entanto, que, no setor privado, esse crescimento foi de $221,2 \%$, quase quatro vezes mais que o apresentado pelo setor público, que cresceu $68,7 \%$, como pode ser evidenciado na Tabela 1, a seguir:

\section{Tabela 1}

Número de instituições de educação superior, cursos e matrículas por categoria administrativa - Brasil: 1996- 2007

\begin{tabular}{c|c|c|c|c|c|c|c|c|c}
\hline \multirow{2}{*}{ Ano } & \multicolumn{3}{|c|}{ Instituiçōes } & \multicolumn{3}{c|}{ Cursos } & \multicolumn{3}{c}{ Matrículas } \\
\cline { 2 - 10 } & Total & Pública & Privada & Total & Pública & Privada & Total & Pública & Privada \\
\hline 1996 & 922 & 211 & 711 & 6.644 & 2.978 & 3.666 & 1.868 .529 & 735.427 & 1.133 .102 \\
\hline 2007 & 2.281 & 249 & 2.032 & 23.488 & 6.596 & 16.892 & 4.880 .381 & 1.240 .968 & 3.639 .413 \\
\hline $\begin{array}{c}0 \% \\
1995-2007\end{array}$ & 147,4 & 18,0 & 185,8 & 253,5 & 121,5 & 366,7 & 161,2 & 68,7 & 221,2 \\
\hline
\end{tabular}

Fonte: Brasil/MEC/INEP, 2008.

Constata-se, ainda, que, em 2007, foram registrados 23.488 cursos de graduação presenciais ofertados pelas IES, no Brasil, sendo 6.596 destes oferecidos por IES públicas e 23.488 por IES privadas, correspondendo a $28,1 \%$ e $71,9 \%$, respectivamente. Observando-se o período de 1996 a 2007, nota-se que o percentual de crescimento de cursos de graduação presenciais foi de $273,5 \%$, em todo o país, sendo essa expansão, nas IES públicas, da ordem de $121,5 \%$, enquanto nas privadas chegou a 366,7\%.

Em relação ao número de instituições da educação superior, a concentração é ainda maior no setor privado. De 2.281 instituiçóes registradas, em 2007, 249 são públicas e 2.032, privadas. Analisandose o período de 1996 a 2007 (ver Tabela 1), observa-se que, no ano de 1996, o número de IES públicas correspondia a 22,9\% das instituições 
do país e o de privadas representava 77,1\%. Em 2007, as IES públicas representavam $10,9 \%$ das instituições, enquanto as privadas chegavam a $89,1 \%$. Ao longo do período analisado, o percentual de crescimento das IES foi de $147,4 \%$, tendo as públicas crescido, apenas, 18,0\%, enquanto as privadas apresentaram expansão de 185,8\%.

Analisando-se a diversificação institucional, os dados expostos na Tabela 2 evidenciam que a forma de organização acadêmica preferencial desse setor é de faculdades, escolas e institutos, com 515 IEs desse tipo, no ano de 1996, passando para 1.569 , em 2007, representando um crescimento de $204,7 \%$. Observa-se, ainda, uma tendência à substituição do modelo de faculdades integradas - que apresentaram um decréscimo de 7,6\%, no período analisado - pelo de centros universitários e centros de educação tecnológica e faculdades tecnológicas, que apresentaram maior crescimento no período pós-LDB. No ano seguinte à aprovação desta Lei, iniciou-se a criação de centros universitários, passando de 13, em 1997, para 166 IES desse tipo, em 2007; uma expansão de $1.177,0 \%$.

Saviani (2007) registra sua indignação com o papel dos centros universitários, afirmando que eles são, de fato, "uma universidade de segunda classe, que não necessita desenvolver pesquisa (...) a fórmula encontrada para burlar o artigo 207 da Constituição Federal” (p. 18). Esses centros universitários se constituem numa forma disfarçada de universidade de ensino, uma vez que passaram a gozar da autonomia constitucional sem a necessidade de realizar pesquisas.

Outra modalidade organizacional que apresentou uma forte expansão, no período, foram os centros de educação tecnológica e faculdades de tecnologia criados a partir de 1999, após a aprovação do Decreto n. 2.208, de 1997. No setor privado, somente em 2001, foram criadas oito instituições dessa natureza. Em apenas seis anos de criação, esse tipo de organização institucional foi o que apresentou o maior crescimento, no setor privado, passando para 138, em 2007, aumentando $1.625 \%$, como é evidenciado na Tabela 2 , na próxima página.

Já o modelo universitário de organização, que representa um custo maior para os mantenedores e do qual, além da realização de ensino, pesquisa e extensão, é exigido, pelo menos, um terço do corpo docente com titulação de mestre ou doutor e em regime de tempo 
Expansão da privatização/mercantilização do ensino superior brasileiro...

integral, apresentou um crescimento pequeno no período, de 36\%, passando, no setor privado, de 64 universidades, em 1996, para 87, em 2007.

\section{Tabela 2}

Número de IES privadas, por organização acadêmica - Brasil: 1996-2007

\begin{tabular}{|c|c|c|c|c|c|c|c|c|c|c|c|}
\hline \multirow[t]{2}{*}{ Ano } & \multicolumn{2}{|c|}{ Universidades } & \multicolumn{2}{|c|}{$\begin{array}{c}\text { Centros } \\
\text { Universitários }\end{array}$} & \multicolumn{2}{|c|}{$\begin{array}{l}\text { Faculdades } \\
\text { Integradas }\end{array}$} & \multicolumn{2}{|c|}{$\begin{array}{l}\text { Faculdades, } \\
\text { Escolas e } \\
\text { Institutos }\end{array}$} & \multicolumn{2}{|c|}{$\begin{array}{l}\text { Centros de } \\
\text { Educação } \\
\text { Tecnológica e } \\
\text { Faculdades de } \\
\text { Tecnologia }\end{array}$} & TOTAL \\
\hline & No & $\%$ & No & $\%$ & No & $\%$ & No & $\%$ & No & $\%$ & \\
\hline 1996 & 64 & 9,0 & 0 & - & 132 & 18,6 & 515 & 72,4 & 0 & - & 711 \\
\hline 2007 & 87 & 4,3 & 116 & 5,7 & 122 & 6,0 & 1.569 & 77,2 & 138 & 6,8 & 2.032 \\
\hline $\begin{array}{c}0 \% \\
1996-2007\end{array}$ & \multicolumn{2}{|c|}{36,0} & \multicolumn{2}{|c|}{ - } & \multicolumn{2}{|c|}{$-7,6$} & \multicolumn{2}{|c|}{204,7} & \multicolumn{2}{|c|}{ - } & 185,8 \\
\hline
\end{tabular}

Fonte: Brasil/MEC/INEP, 2008.

Os dados acima evidenciam o resultado da política de expansão das IES privadas adotada no Brasil, a partir da promulgação da LDB/ 1996, o que possibilitou a constituição dessas instituições como empresas com fins lucrativos. A liberalização e a desregulamentação desse setor, com a flexibilização das regras para abertura de cursos e novas instituições, as isenções tributárias, as bolsas de estudos para alunos carentes, por meio do programa do Crédito Educativo, hoje transformado no Fundo de Financiamento ao Estudante do Ensino Superior (FIES), os empréstimos financeiros a juros baixos por instituições bancárias oficiais, como o Banco Nacional de Desenvolvimento Econômico e Social (BNDES), o PROUNI, entre outras formas de estímulo, contribuíram de forma decisiva para a expansão da mercantilização do ensino superior.

Outro aspecto significativo para a análise da política de privatização em curso, no país, é o fato de que o acelerado crescimento do ensino superior evidenciado acima assumiu novas configurações, nos últimos anos, no âmbito do setor produtivo, seja pela criação de instituiçôes denominadas universidades coorporativas, ${ }^{4}$ por empresas multinacionais, como Fiat, Ford, IBM, MacDonald's (Universidade do 
Hamburguer), seja pela criação de oligopólios, por meio da fusão de instituiçôes e pela negociação de suas ações nas bolsas de valores. Com a entrada no mercado de ações, a rede privada de ensino superior, no Brasil, movimenta, aproximadamente, 15 bilhões de reais por ano (Erthal \& Perosim, 2007). Como se dá esse processo? Que implicações traz para a qualidade da educação superior brasileira? É disso que vamos tratar a seguir.

\section{A formação de oligopólios no ensino superior privado}

Desde 2007, o processo de mercantilização do ensino superior brasileiro vem adquirindo novos contornos. Observa-se um forte movimento de compra e venda de IES no setor privado. Além das fusões, que têm formado gigantes da educação, as "empresas de ensino" agora abrem o capital na bolsa de valores, com promessa de expansão ainda mais intensa e incontrolável. São quatro as empresas educacionais que mais se destacam nesse mercado de capitais: a Anhanguera Educacional s.A., com sede em São Paulo; a Estácio Participaçôes, controladora da Universidade Estácio de Sá, do Rio de Janeiro; a Kroton Educacional, da Rede Pitágoras, com sede em Minas Gerais; e a empresa SEB S.A., também conhecida como "Sistema COC de Educação e Comunicação”, com sede em São Paulo. É importante ressaltar que grande parte do capital dessas empresas é oriunda de grupos estrangeiros, em especial, de bancos de investimentos norte-americanos, que encontraram, nesse setor, um mercado muito favorável ao aumento de seus lucros.

A abertura do capital dessas empresas ao mercado de ações e a valorização destas últimas possibilitam o aumento de seu capital, a compra de outras instituições menores, espalhadas no país, e, com isso, a formação de grandes grupos empresariais, também denominados "redes". Como passam a adquirir materiais e equipamentos em grandes quantidades, conseguem reduzir seus custos operacionais e aumentar suas margens de lucro e, assim, podem diminuir os valores das mensalidades. Com o crescimento desses grandes grupos empresariais e a redução das mensalidades cobradas por eles, as pequenas faculdades não conseguem se manter no mercado e acabam sendo vendidas. A maioria das instituições adquiridas por essas grandes empresas são de porte pequeno ou médio, estão localizadas no interior do país e endividadas. 
Expansão da privatização/mercantilização do ensino superior brasileiro...

Como resultado desse processo de compra/fusão de IES, a tendência é a formação de oligopólios (número reduzido de grandes empresas que atuam num segmento do mercado), que passarão a ter o controle do mercado da educação superior do país. A imprensa e a mídia eletrônica nacionais têm noticiado esse movimento de fusões, como evidenciado, por exemplo, na matéria "A expansão do ensino privado", publicada pelo jornal O Estado de S. Paulo (2007):

Em busca de capital para poder fazer essas aquisições, três corporações do setor de ensino - a Estácio de Sá, a Anhanguera Educacional e a Rede Pitágoras - captaram cerca de $\mathrm{R} \$ 1,2$ bilhão nos últimos meses, por meio do lançamento de títulos, participação acionária de bancos de investimento e aportes de fundos de private equity, que preparam as empresas para o crescimento, profissionalizam sua gestão e implementam projetos de governança administrativa. Sediada em Ribeirão Preto, a rede COC já ajustou seu estatuto às regras do nível 2 de governança da BOVESPA. Recentemente, a Faculdade Jorge Amado, em Salvador, vendeu 60\% de seu capital a um grupo de investidores americanos. Dois grandes fundos, um deles dirigido pelo ex-presidente do Banco Central Armínio Fraga, compraram $30 \%$ de uma faculdade de Fortaleza.

A Anhanguera Educacional foi a primeira empresa do setor a aderir ao mercado de capitais, desde 2007, tornando-se a empresa líder em aquisições e fusões de IES, ocupando, atualmente, a posição de destaque no setor de ensino superior privado do Brasil. Como resultado dessa entrada nas bolsas, a empresa ganhou novo impulso e expandiu seus serviços. Após seis meses de operações no mercado de ações, a instituição colocou $28 \%$ de seu capital à venda, obtendo $70 \%$ de valorização de suas ações nesse período. A participação de fundos de investimento nessa transação e a entrada na Bolsa de Valores de São Paulo (BOVESPA), que passou a negociar as ações dessa empresa, valorizaram o patrimônio do grupo, que passou de 1,7 bilhão para 3 bilhões de reais, em menos de um ano (Cf. Nilnews@Kimindas Atualidades, 2008).

No ano de 2008, a Anhanguera continuou mantendo a liderança nas fusões, acumulando a aquisição de 18 instituições, desde o ano de 2007, transformando-se numa megainstituição, com 52 unidades distribuídas nos estados de São Paulo, Goiás, Santa Catarina, Rio Grande do Sul, Mato Grosso, Mato Grosso do Sul e Distrito Federal. Com essas novas aquisições, segundo a mesma notícia já citada, a rede 
Anhanguera passou a ser a maior empresa do setor privado de educação superior, com 720 mil alunos matriculados (incluindo alunos de cursos de graduação e pós-graduação, profissionalizantes, presenciais e a distância). A maior parte das ações da Anhanguera Educacional pertence ao grupo Pátria Investimentos que, por sua vez, como registra seu web site, tem parcerias com os bancos de investimento norte-americanos Salomon Brothers e Oppenheimer.

Na mesma linha, a Estácio Participações, controladora da Universidade Estácio de Sá, do Rio de Janeiro, faturou R \$ 447 milhões, até julho de 2008. A Estácio Participações possui 23 unidades de ensino distribuídas em 16 estados do Brasil (Amapá, Pará, Ceará, Rio Grande do Norte, Pernambuco, Alagoas, Sergipe, Bahia, Minas Gerais, Espírito Santo, Rio de Janeiro, São Paulo, Santa Catarina, Paraná, Mato Grosso do Sul e Goiás), com 207.079 alunos matriculados em cursos de graduação presenciais e a distância. Em 2008, a empresa expandiuse, também, para o Paraguai, onde possui 1.686 alunos matriculados.

Outra empresa do ramo educacional que seguiu o mesmo caminho de fusão e abertura de capital na bolsa de valores foi a Kroton Educacional, da Rede Pitágoras, de Minas Gerais, que, desde 2001, expandiu seus "negócios" educacionais para o ensino superior, com a entrada da Apollo International (sediada no estado do Arizona, nos Estados Unidos) como sua acionista. Em 31 de dezembro de 2008, a Kroton possuía um patrimônio líquido de $\mathrm{R} \$ 440,9$ milhões, como registram as "Informações Financeiras" disponíveis no web site da empresa (ver Kroton Educacional, 2009). A partir de 2005, passou também a oferecer cursos de formação de tecnólogos, com duração de dois a dois anos e meio, por meio da marca "INED". Quando este grupo chegou à BOVESPA, possuía apenas oito faculdades e, somente em um ano, já possui 25 IES, espalhadas pelo país.

O Sistema COC de Educação e Comunicação é mais uma empresa que também iniciou seus negócios na educação básica e, a partir de 2000, expandiu sua atuação para o ensino superior, por meio das $\mathrm{Fa}$ culdades COC, oferecendo cursos de graduação presenciais e, em 2005, ampliou sua oferta de serviços educacionais com a implantação da educação a distância. Em outubro de 2007, esta rede passou a se chamar Sistema Educacional Brasileiro (SEB S/A) e ingressou na bolsa de valores, abrindo seu capital na BOVESPA. A expansão foi imediata. Em 2008, 
Expansão da privatização/mercantilização do ensino superior brasileiro...

o grupo empresarial adquiriu a Faculdade Metropolitana, de Belo Horizonte (MG), e a Faculdade Dom Bosco, de Curitiba (PR), passando a atender 8.934 alunos, em cursos de graduação presenciais, nas unidades de Araçatuba e Ribeirão Preto (SP), Belo Horizonte (MG), Curitiba (PR) e Salvador (BA). Sua maior atuação se faz por meio da EaD, com 19.875 alunos matriculados em cursos de graduação semipresenciais (com encontros presenciais semanais), na Faculdade Interativa COC. Com sede na cidade de São Paulo, a empresa possui unidades próprias nos estados do Espírito Santo, São Paulo, Bahia, Alagoas, Goiás, Minas Gerais, Paraná e no Distrito Federal (Brasília). O lucro líquido do Grupo, em 2008, foi de $\mathrm{R} \$ 66,3$ milhões, com um crescimento de 97,9\% em relação ao ano de 2007 (Sistema Educacional Brasileiro, 2009).

Essa expansão descontrolada do ensino superior privado está vinculada, no Brasil, a processos intensos da desnacionalização da educação. A entrada de capitais estrangeiros no mercado educacional tem sido a marca desse processo. $\mathrm{O}$ grupo americano Laureate foi o primeiro a se tornar sócio de uma universidade brasileira, a Anhembi-Morumbi, em 2005. Desde então, vários outros grupos empresariais estrangeiros têm adquirido ações das empresas educacionais que atuam no ensino superior, como o GP Investimentos (que comprou 20\% da Estácio de Sá); o UBC pactual (que possui $38 \%$ das faculdades do Nordeste); o Fundo Pátria (com ações da Anhanguera); o Capital Group (que possui ações no Grupo Kroton) e, mais recentemente, o Cartesian Group, que adquiriu parte do grupo nordestino Maurício de Nassau (Iwasso, 2009).

Mais um sinal de que a exploração mercantil da educação se tornou um bom negócio pode ser constatado pelo faturamento apresentado pelas empresas que atuam nesse setor, que tiveram um crescimento significativo, de mais de 25\%, passando de R \$ 44 bilhôes, em 2002, para $\mathrm{R} \$ 55$ bilhões, em 2008. Seus lucros passaram a ser comparáveis, proporcionalmente, a empresas de grande porte, como a Vale do Rio Doce, a Gerdau e a PETROBRÁs, segundo relatório publicado pelo jornal Valor Econômico (CONTEE, 2007). Observa-se, assim, que, com esse tipo de comercialização da educação superior, o Brasil entra, efetivamente, no setor de serviços comerciais, conforme definiu a Organização Mundial do Comércio (OMC).

$\mathrm{Na}$ ótica dos empresários do setor, esse mercado é muito competitivo, em especial, após a entrada de grupos estrangeiros na aquisição 
das ações de empresas nacionais nas bolsas de valores. A compra de IES vem garantindo o fortalecimento e a consolidação desses grandes grupos empresariais, diante do cenário de crise e de acirramento da competição.

Os lucros exorbitantes e a sua atratividade no mercado de ações, entretanto, não têm nenhuma relação com a qualidade de ensino. Afinal, não é este o objetivo. Uma prova disso pode ser constatada nos resultados dos exames da Ordem dos Advogados do Brasil (OAB). Segundo reportagem da revista Carta Capital (Erthal \& Perosim, 2007), menos de $10 \%$ dos formados no curso de Direito do Centro Universitário Ibero-Americano, em São Paulo, e da Faculdade Comunitária, de Campinas, ambas da Rede Anhanguera, foram aprovados. Por outro lado, dados do INEP comprovam que grande parte dessas instituições não atende às exigências de um terço do corpo docente com titulação de mestres e doutores e em regime integral de trabalho, definidas na LDB. Com isso, a precarização da função docente acaba se refletindo na própria qualidade do ensino ofertado.

\section{Considerações finais}

A acelerada expansão do ensino superior privado, no país, se deu a partir do discurso prepotente de que o mercado é bom empreendedor e que a privatização deve ser o dogma central a ser adotado. A LDB é a expressão desse momento e desse contexto e acabou sendo decisiva para a criação do mercado educacional.

Sob a lógica da mercantilização da educação superior, com vistas a adequar esse nível de ensino às demandas do capital financeiro internacional, em busca de novos mercados para manter sua hegemonia, são implantadas reformas pautadas por uma política privatista e de desmonte do Estado social. Consolida-se, assim, o empresariamento da educação,

(...) transformando a universidade, no seu conjunto, numa empresa, uma entidade que não se produz apenas para o mercado, mas que produz a si mesma como mercado, como mercado de gestão universitária, de planos de estudo, de certificação, de formação de docentes, de avaliação de docentes e estudantes. (Santos, 2004, p. 18-19)

O processo de mercantilização do ensino superior brasileiro, evidenciado nesse estudo, adquire nova configuração com a formação dos 
Expansão da privatização/mercantilização do ensino superior brasileiro...

oligopólios (grandes empresas privadas que controlam a maioria dessa oferta educacional), a partir das fusões e compras de instituições pequenas e da abertura do capital nas bolsas de valores. A expansão descontrolada e mercantil desse nível de ensino está vinculada a processos intensos de desnacionalização da educação, no Brasil, com a entrada de capitais estrangeiros no mercado educacional, introduzindo, efetivamente, a educação no setor de serviços a serem negociados na OMC.

Esse "novo" modelo organizacional é movido pela ideologia do valor econômico e do marketing e fundamenta-se em princípios neoliberais como flexibilidade, racionalidade, produtividade e competitividade, transformando a educação superior em negócio altamente lucrativo. No excerto a seguir, Apple (2001, p. 18) sintetiza a mudança da concepção de educação provocada pelo neoliberalismo:

(...) o que outrora foi um conceito e uma prática política apoiados numa negociação e diálogo colectivo é, hoje em dia, um conceito "totalmente" econômico. Actualmente, debaixo da influência do neoliberalismo, o verdadeiro significado de cidadania foi radicalmente transformado. Nos dias de hoje, em muitos países, o cidadão é simplesmente um consumidor. $\mathrm{O}$ mundo é visto como um vasto supermercado. As escolas e inclusive os nossos alunos (...) tornam-se mercadorias que são compradas e vendidas do mesmo modo como se compram e vendem outro gênero de mercadorias.

Como consequência, a educação é transformada num grande "negócio" a ser comercializado no mercado capitalista e os estudantes, em clientes-consumidores, disputados por instituições privadas de ensino superior que reproduzem, em seu interior, relações capitalistas, por meio de práticas instrumentais e utilitaristas, distanciando-se da reflexão crítica e da educação como possibilidade emancipadora.

Recebido em agosto de 2009 e aprovado em janeiro de 2010.

\section{Notas}

1. Os pressupostos básicos da reforma do Estado no Brasil estão especificados no Plano Diretor da Reforma do Aparelho do Estado (PDRE), publicado em novembro de 1995, que "define objetivos e estabelece diretrizes para a reforma da administração pública brasileira”. Nesse plano, são definidas as atividades que devem ficar sob a responsabilidade direta do Estado, as que este deve coordenar e/ou supervisionar e as que deve entregar à iniciativa 
privada. De acordo com esse Plano, a educação superior pública seria um serviço não exclusivo do Estado e as instituições de ensino superior públicas deveriam ser transformadas em "organizações sociais" (cf. Bresser-Pereira, 1998).

2. O "Programa Universidade para Todos" (PROUNI) instituído pela MP n. 213/2004, convertida na Lei n. 11.096, em 13 de janeiro de 2005, regulamentada, esta última, pelo Decreto n. 5.493, de 18 de julho de 2005, é um programa do governo federal que se destina à extensão dos benefícios fiscais que as IES filantrópicas já possuíam a todas as instituiçôes de ensino superior privadas, em "troca" de preenchimento das "vagas ociosas" por alunos "carentes" (afrodescendentes, portadores de necessidades especiais, indígenas, ex-presidiários), por meio de bolsas integrais e parciais (50\% e $25 \%$ ).

3. Esses dois elementos estão estabelecidos no documento "La enseñanza superior: las lecciones derivadas de la experiencia", publicado em 1995 pelo Banco Mundial, no qual são apresentadas as diretrizes para a reforma da educação superior, na América Latina, Ásia e Caribe.

4. Essa denominação, bem como a respectiva caracterização institucional e acadêmica são, ainda, objeto de questionamentos e controvérsia. Sobre esse assunto, ver Otranto (2008).

\section{Referências}

AMARAL, N.C. Financiamento da educação superior: Estado x mercado. São Paulo: Cortez; Piracicaba: UnIMEP, 2003.

APPLE, M.W. Reestruturação educativa e curricular e as agendas neoliberal e neoconservadora: entrevista com Michael Apple. Currículo sem Fronteiras, v. 1, n. 1, p. 5-33, jan./jun. 2001. Disponível em: $<$ http://www.curriculosemfronteiras.org/vol1 iss1 articles/apple.pdf>.

BANCO MUNDIAL. La enseñanza superior: las lecciones derivadas de la experiencia. Washington, DC: BIRD; Banco Mundial, 1995.

BOVESPA. Empresas. Anhanguera Educacional Participaçôes S.A. Disponível em: <http://www.bovespa.com.br/Empresas/InformacoesEmpresas/ ExecutaAcaoConsultaInfoEmp.asp?codCVM=18961>. Acesso em: 10 abr. 2009.

BRASIL. Decreto n. 2.208, de 17 de abril de 1997. Regulamenta o $\$ 2^{\circ}$ do art. 36 e os arts. 39 a 42 da Lei n. 9.394, de 20 de dezembro de 1996, que estabelece as Diretrizes e Bases da Educação Nacional. Diário Oficial da União, Brasília, DF, 18 abr. 1997b. (Revogado pelo Decreto n. 5154/2004). Disponível em: <http://www.planalto. gov.br/ccivil_03/decreto/D2208.htm>

BRASIL. Decreto n. 2.306, de 19 de agosto de 1997. Regulamenta, para o Sistema Federal de Ensino, as disposiçôes contidas no art. 10

Educ. Soc., Campinas, v. 31, n. 111, p. 481-500, abr.-jun. 2010

Disponível em <http://www.cedes.unicamp.br> 
Expansão da privatização/mercantilização do ensino superior brasileiro...

da Medida Provisória n. 1.477-39, de 8 de agosto de 1997, e nos arts. $16,19,20,45,46$ e $\$ 1^{\circ}, 52$, parágrafo único, 54 e 88 da Lei n. 9.394, de 20 de dezembro de 1996, e dá outras providências. Diário Oficial da Uniāo, Brasília, DF, 6 abr. 1997a. (Revogado pelo Decreto n. 3.860, de 9 de julho de 2001).

BRASIL. Decreto n. 3.860, de 9 de julho de 2001. Dispõe sobre a organização do ensino superior, a avaliação de cursos e instituições, e dá outras providências. Diário Oficial da União, Brasília, DF, 10 jul. 2001a. (Revogado pelo Decreto n. 5.773, de 2006).

BRASIL. Decreto n. 4.914, de 11 de dezembro de 2003. Dispõe sobre os centros universitários de que trata o art. 11 do Decreto n. 3.860, de 9 de julho de 2001, e dá outras providências. Diário Oficial da Uniāo, Brasília, DF, 12 dez. 2003 (Ed. Extra). (Revogado pelo Decreto n. 5.786, de 24 de maio de 2006).

BRASIL. Decreto n. 5.493, de 18 de julho de 2005. Regulamenta a Lei n. 11.096, de 13 de janeiro de 2005, que instituiu o Programa Universidade para Todos (Prouni). Diário Oficial da União, Brasília, DF, 19 jul. 2005a.

BRASIL. Decreto n. 5.622, de 19 de dezembro de 2005. Regulamenta o art. 80 da Lei n. 9.394, de 20 de dezembro de 1996. Diário Oficial da União, Brasília, DF, 20 dez. 2005 b.

BRASIL. Lei n. 9.394, de 20 de dezembro de 1996. Estabelece as Diretrizes e Bases da Educação Nacional. Diário Oficial da União, Brasília, DF, 23 dez. 1996.

BRASIL. Lei n. 10.260, de 12 de julho de 2001. Dispõe sobre o Fundo de Financiamento ao Estudante do Ensino Superior (FIES) e dá outras providências. Diário Oficial da União, Brasília, DF, 13 jul. 2001. (Alterada pela Lei n. 11.552, de 19 de novembro de 2007, publicada no Diário Oficial da União, em 31 maio 2007; Ed. Extra).

BRASIL. Lei n. 11.096, de 13 de janeiro de 2005. Institui o Programa Universidade para Todos (Prouni). Diário Oficial da União, Brasília, DF, 14 jan. 2005.

BRASIL. Ministério da Administração Federal e Reforma do Estado (MARE). Plano Diretor da Reforma do Estado. Brasília, DF: MARE, 1995. 
BRASIL. Ministério da Educação. Instituto Nacional de Pesquisas Educacionais Anízio Teixeira. Censo da Educação Superior (1996 a 2007). Brasília, DF: INEP, 2008. Disponível em: <http://www.inep. gov.br/superior/censosuperior/sinopse/>. Acesso em: 10 fev. 2009.

BRESSER-PEREIRA, L.C.; SPINK, P. (Org.). Reforma do Estado e administração pública. Rio de Janeiro: FGV, 1998.

CATANI, A.M.; OLIVEIRA, J.F. A educação superior. In: Oliveira, R.P.; Adriâo, T. (Org.). Organização do ensino no Brasil: níveis e modalidades na Constituição Federal e na LDB. 2. ed. São Paulo: Xamã, 2007. p. 73-84.

CHAUI, M. A universidade operacional. Avaliação, Campinas, v. 4, n. 3, p. 3-8, 1999.

CHAVES, V.L.J. Crise e privatização da universidade pública: de Fernando Henrique a Lula da Silva. Universidade \& Sociedade, Brasília, DF, n. 38, p. 61-77, 2006.

EDUCAÇÃO: Anhanguera compra rede e será líder do setor. Nilnews@Kimindas Atualidades, 8 out. 2008 [online]. Disponível em: <http://kiminda.wordpress.com/2008/10/08/educacao-anhangueracompra-rede-e-sera-lider-do-setor/>. Acesso em: 20 mar. 2009.

ERTHAL, J.M.; PEROSIM, L. O ensino vai à Bolsa. Carta Capital, São Paulo, n. 466 - especial, p. 10-15, 17 out. 2007.

A EXPANSÃO do ensino privado. O Estado de S. Paulo [online], São Paulo, Opinião, 30 jul. 2007. Disponível em: <http://www.estadao.com.br/ estadaodehoje/20070730/not_imp26931,0.php>. Acesso em: 20 abr. 2009.

IWASSO, S. Crise breca fusões e aquisições no ensino superior. $O E$ stado de S. Paulo [online], São Paulo, 27 abr. 2009. Disponível em: <http://www.estadao.com.br/estadaodehoje/20090427/not_imp360930,0.php>. Acesso em: 28 abr. 2009.

KROTON EDUCACIONAL [web site]. Disponível em: <http:// www.mzweb.com.br/kroton/web/arquivos/Kro-ton_APR_2T09_port. pdf>. Acesso em: 20 mar. 2009.

KROTON EDUCACIONAL. Informações Financeiras. Disponível em: <http://www.mzweb.com.br/kroton/web/conteudo_pt.asp?idioma= 
Expansão da privatização/mercantilização do ensino superior brasileiro...

0\&tipo=7931\&submenu=3\&img=6370\&conta $=28>$. Acesso em: 20 mar. 2009.

OS NÚMEROS da mercantilização da educação superior. CONTEE Notícias [online], Brasília, DF, 19 out. 2007. Disponível em: <http:// www.contee.org.br/noticias/contee/nco6asp >. Acesso em: $10 \mathrm{mar}$. 2009.

OTRANTO, C.R. Universidades corporativas: subsídios para o debate. Universidade \& Sociedade, Brasília, DF, v. 7, n. 41, p. 33-41, 2008.

PÁTRIA Investimentos [web site]. Disponível em: <http://www. patriainvestimentos.com.br/site/>. Acesso em: 10 abr. 2009.

SANTOS, B.S. A universidade no século XXI: para uma reforma democrática e emancipatória da universidade. São Paulo: Cortez, 2004.

SAVIANI, D. Da nova $L D B$ ao FUNDEB: por uma outra política educacional. Campinas: Autores Associados, 2007.

SISTEMA EDUCACIONAL BRASILEIRO (SEB S./A.) [online]. SEB divulga resultados de 2008 com forte crescimento. São Paulo, 17 mar. 2009. Disponível em: <http://www.mzweb.com.br/seb/web/arquivos/ SEB_ER_4T08_port.pdf> Acesso em: 28 abr. 2009. 